\title{
A model of health education and management for osteoporosis prevention
}

\author{
LIANG WANG $^{1 *}$, XIAOWEN XU $^{1 *}$, YAN ZHANG ${ }^{2}$, HONGXIA HAO $^{1}$, LIYING CHEN $^{1}$, TIANJIAO SU ${ }^{1}$, \\ YAN ZHANG $^{1}$, WEIFENG MA ${ }^{1}$, YUANYUAN XIE ${ }^{1}$, TIANTIAN WANG ${ }^{1}$, FAN YANG $^{1}$, \\ LI HE $^{3}$, WENJIAO WANG ${ }^{1}$, XUEMEI FU ${ }^{1}$ and YUANZHENG MA ${ }^{1}$ \\ ${ }^{1}$ Center of Orthopedics, The 309th Hospital of People's Liberation Army, Beijing 100091; \\ ${ }^{2}$ Center for Systems Biomedical Sciences, University of Shanghai for Science and Technology, Shanghai 200093; \\ ${ }^{3}$ Division of Science and Technology, National Institute for Nutrition and Food Safety, \\ Chinese Center for Disease Control and Prevention, Beijing 100050, P.R. China
}

Received March 31, 2015; Accepted June 23, 2016

DOI: 10.3892/etm.2016.3822

\begin{abstract}
Osteoporosis, a chronic disease with no therapeutic cure, affects a growing number of people as the aging population in China rapidly increases. Therefore, developing an evidence-based model of health education and management for osteoporosis prevention is required. In the present study, an osteoporosis club was established, which is a novel model of health education and management for osteoporosis prevention. A unified management of membership was used based on a digitized database. A total of 436 patients with osteoporosis were randomly assigned to the osteoporosis club group or the self-management control group. For the osteoporosis club group, multiple activities of health education were performed, including monthly systematic health education lectures, exercise programs and communication parties once a year. For the control group, the participants took charge of their own musculoskeletal health. All data of the participants were collected and evaluated prior to and following intervention. In the pre-intervention assessment, no significant difference was identified in the health education between the two groups. Through the four-year intervention, the osteoporosis knowledge, health beliefs, living behavior, medication compliance, quality of life and bone mineral density of the osteoporosis club group were improved significantly compared with the control group $(\mathrm{P}<0.001)$, while the pain degree of the osteoporosis club group was relieved significantly more compared with the control group $(\mathrm{P}<0.001)$. The results in the present
\end{abstract}

Correspondence to: Professor Yuanzheng Ma, Center of Orthopedics, The 309th Hospital of People's Liberation Army, 17 Heisanhu Road, Beijing 100091, P.R. China

E-mail: yuanzhengmacn@126.com

*Contributed equally

Key words: osteoporosis, health education, compliance, bone mineral density, quality of life study suggest that setting up an osteoporosis club is an evidence-based model of health education and management for osteoporosis prevention in China.

\section{Introduction}

Osteoporosis, which is characterized by low bone mineral density (BMD) and deterioration of bone tissue (1), results in fragility fractures that occur prior to patient recognition. Fragility fractures, primarily comprising hip, vertebral, forearm and humeral fractures, are one of the most serious consequences of osteoporosis (2). For osteoporosis patients with a hip fracture, $\sim 30 \%$ experience a reduction in their functional capacity for daily living compared with pre-fracture levels (3), and $>20 \%$ succumb to mortality within 6 to 12 months after the fracture (4). As the aging population in Asia increases, the morbidity of hip fractures in this region is expected to increase from a quarter of the world's total in 1990 to approximately half by 2050 (1,5). Furthermore, half of the elderly Asian population are Chinese, comprising $20 \%$ of the elderly population worldwide (6). Therefore, the challenge of osteoporosis prevention in China is serious.

Osteoporosis is a chronic illness similar to hypertension and diabetes (7), with no ideal pharmacological agent yet identified to cure it. Thus, health education and management for patients with osteoporosis, which could improve the knowledge of osteoporosis prevention and compliance, are required to decrease fragility fracture and refracture, and to increase the quality of life. National and international consensus educational programs and management consist of three overall themes: i) Knowledge of osteoporosis; ii) medication and diet; and iii) exercise (8). For instance, the Osteoporosis Prevention and Self-Management Course is used for chronic illnesses and is developed by the Arthritis Foundation of Victoria and utilized by the Osteoporosis Australia Charity; the course aims to increase knowledge and improve confidence, awareness and self-management for osteoporosis prevention. It emphasizes promoting appropriate lifestyle changes, including an increase in calcium intake, increasing appropriate physical activity and smoking cessation (9). An 
additional example is the Evidence-Based Guideline for the Prevention of Osteoporosis and Osteoporotic Fractures in Community Health, which was written in Japanese and used for the prevention of osteoporosis. It was published in October 2004 and includes a total of eight areas of health education, namely, food and nutrient intake, exercise, exposure to sunlight, weight management, smoking and alcoholic beverage drinking control and prevention from falling (10). However, the interventions of these projects were not always used by patients and doctors, and the effects amongst patients were controversial $(11,12)$. Gianoudis et al $(13)$ proposed the 'Osteo-cise: Strong Bones for Life' study, which consisted of a multi-modal exercise and osteoporosis education program, and was a community-based scheme for elderly adults at risk of falls and fractures. However, the results have not yet been reported.

No scientific consensus modes of health education and management for osteoporosis prevention have been proposed worldwide, particularly in China. In the present study, an osteoporosis club was established as a novel model of health education and management for osteoporosis prevention, and a unified management of membership based on a digitized database was adopted. Multiple activities of health education were performed, including monthly systematic health education lectures and exercise programs and communication parties once a year. The present study evaluates the effect of the osteoporosis club and discusses the novel model of health education and management for osteoporosis prevention.

\section{Patients and methods}

Study design. The present study was a randomized, controlled, parallel-group comparison trial, with evaluators blinded to the allocation. It was managed by the Department of Orthopedics at the 309 Hospital of People's Liberation Army (PLA) (Beijing, China).

Participants. A total of 436 patients with osteoporosis, including 139 males with an average age of $66.55 \pm 10.98$ years and 297 females with an average age of $68.85 \pm 9.01$ years, were invited to participate in the study. The sample collection was performed between January and June 2010 in the osteoporosis outpatient service at the 309 Hospital of PLA. The present study was conducted in accordance with the declaration of Helsinki and was approved by the Ethics Committee of the 309th Hospital of PLA. Written informed consent was obtained from all participants.

Inclusion and exclusion criteria. The inclusion criteria included patients diagnosed with osteopenia [T-score between -1.0 and -2.5 standard deviation (SD)] or osteoporosis (T-score, $\leq-2.5 \mathrm{SD}$ ), determined via a dual-energy X-ray absorptiometry (DEXA) according to the WHO criteria for osteoporosis (14), or patients with a history of one or more fragility fractures verified by radiography. Participants who were suffering from particular illnesses that could induce bone metabolism disorders, including hypohepatia, renal insufficiency, thyroid disorder, parathyroid disease, hematological disease, desmosis, multiple myeloma, bone metastases and hypercortisolism, were excluded from the study.
Randomization. The participants were randomly assigned to the osteoporosis club or the self-management control group, and stratified by gender. To reduce potential contamination, any couples enrolled in the present study were randomized into the same group. The course was managed by an independent staff member not involved in the study.

Osteoporosis club. Setting up an osteoporosis club as a health education and management platform is a novel model for osteoporosis prevention in China. The model adopted a unified management of membership by establishing a digitized database to collect the information of the participants, formulate the individual therapeutic schedule for each participant and monitor their conditions. Multiple activities of health education and management were performed, including monthly systematic health education lectures, exercise programs and communication parties once a year. The participants could receive gifts from the club, such as calcium tablets, vitamin D and an information brochure for osteoporosis prevention, and could perform the DEXA test for free.

Systematic health education lecture. Osteoporosis is a chronic illness that is similar to hypertension and diabetes, and no ideal pharmacological agent has been identified to cure it. Thus, the knowledge about osteoporosis is the base for osteoporosis prevention. To provide systematic health education lectures, the osteoporosis club organized an integrated team of training specialists composed of orthopedists, nutritionists, endocrinologists, psychological counselors and rehabilitation therapists. The training specialists were required to attend regular ongoing education workshops that covered information about the latest research on osteoporosis, current treatments available and management options, basic nutrition for healthy bones, exercises for osteoporosis, psychological health, and educational skills and strategies. The participants shared experiences in the workshop and learned from one another how to improve the quality of training lectures. The systematic health education lectures were held once a month, and the content involved knowledge and understanding of the risk factors for osteoporosis and preventive measures, including diet guidance, exercise coaching, drug therapy, psychological intervention and rehabilitation direction. The participants received knowledge brochures for osteoporosis prevention and communicated with the training specialists of the club if they had any questions with regards to fitness.

Exercise program. Osteoporosis patients are associated with limitations in their functional capacity, pain, reduced social participation, reduced quality of life and fear of falling $(15,16)$. Exercise is often recommended to manage osteoporosis for its benefits of increasing the bone diameter and optimizing balance and muscle function (17). The exercise program of the osteoporosis club consisted of two parts: Training and outdoor sports. The training consisted primarily of moderate-impact weight-bearing exercises, including spinal stability exercises, limb muscle stabilization exercises and postural corrections. It was performed in the training lecture and practiced at home. Outdoor sports, including climbing and outdoor activities, were organized by the osteoporosis club. 
Communication party. All of the members, including the training specialists, were gathered together to hold a communication party once a year. An annual summary and shows were presented in the party. It was a platform in which the participants could share their experiences and acquire information regarding osteoporosis. Furthermore, this club communication party could encourage trust between doctors and patients, thereby promoting friendships between them.

Self-management control group. This group was monitored via in the osteoporosis outpatient service. The participants that were assigned to this group primarily took charge of their own musculoskeletal health and sought further medical information from the Internet, TV shows, health magazines and outpatient service consultations. The information of this group was collected into the digital database, and the participants underwent the same testing protocol as the intervention group.

Outcome measures and follow-up. The observed duration of the present study lasted for four years. All the participants were assessed at baseline and four years after the baseline. Patient general information, knowledge and health beliefs of osteoporosis, behavior of living, medication compliance, pain degree and quality of life were collected by filling in questionnaires, and the BMDs were tested via DEXA. All the data were inputted into a digital database.

General information. All of the general information of the participants, including gender, age, height, weight and body mass index (BMI), were inputted into the digital database.

Knowledge and health beliefs. The participant's knowledge and health beliefs related to osteoporosis were evaluated by the Osteoporosis Knowledge Tests (OKT) and the Osteoporosis Health Belief Scale (OHBS) $(18,19)$. The OKT, which was translated and modified into a Chinese version, is a 26-item instrument used for measuring osteoporosis knowledge and has been proven to have satisfactory reliability and validity for the Chinese population. In a previous study, the Cronbach's alpha reliability coefficients ranged between 0.83 and 0.87 , and the test-retest correlation coefficients ranged between 0.75 and 0.82 (20). The participants acquired 1 point for a correct answer and 0 points for an incorrect answer, and were scored on their answered items ranging between 0 and 26. The OHBS, which was translated into Chinese without modification, includes seriousness, health motivation, calcium benefits, calcium barriers, exercise benefits and exercise barriers (19). It has been proven to have satisfactory reliability and validity for the Chinese population. In a previous study, the Cronbach's alpha reliability coefficients ranged between 0.68 and 0.85 , and the test-retest Pearson correlation coefficients ranged between 0.36 and 0.82 (20). In the present study, the participants estimated each of the 42 items with the following 5-point scale: 1-strongly disagree; 2-disagree; 3-neutral; 4-agree; and 5-strongly agree.

Living behavior. The statistical numbers of those who have good living behavior for osteoporosis prevention, including sufficient outdoor sunshine ( $\geq 4 \mathrm{~h} /$ week), drinking milk every day ( $\geq 250 \mathrm{ml}$ ), adequate exercise ( $\geq 3$ times/week), no alcohol intake and no smoking, were inputted into the digitized database at baseline and four years after baseline.

Medication compliance. Medication compliance was evaluated by comparing the numbers of those patients who continued to receive medication, including calcium, vitamin $\mathrm{D}$ or other medicines. The information regarding receiving medication was collected using a questionnaire, which was inputted into the digitized database at baseline and four years after baseline.

Pain degree evaluation. A significant number of patients with osteoporosis suffer from pain (15). In the present study, the pain degree of the participants was evaluated by visual analogue scales (VAS), which is a continuous graphical rating scale (21). It is a measurement instrument for subjective characteristics or attitudes that cannot be directly measured. This test yields a score between 0 and 10 , where 0 represents no pain and 10 represents extreme pain.

Appraisal of life quality. Osteoporosis can decrease the quality of life and is associated with limitations in the functional capacity, pain, reduced social participation and fear of falling (22). In the present study, the quality of life was evaluated using the MOS 36-item Short Form Health Survey (SF-36), which comprised of physical functioning (PF), role physical (RP), bodily pain (BP), general health $(\mathrm{GH})$, vitality (VT), social functioning (SF), role emotional (RE) and mental health $(\mathrm{MH})$. Each domain was scored on a standardized scale with values ranging between 0 and 100, where 0 represents the lowest, and 100 represents the highest, quality of life (23). The SF-36, which was translated and modified into Chinese, has been proven to have satisfactory reliability and validity for the Chinese population. In a previous study, the Cronbach's alpha reliability coefficients ranged between 0.72 and 0.88 , and the test-retest correlation coefficients ranged between 0.66 and $0.94(24)$

$B M D$. The BMD of the participants was measured at the lumbar spine (L2-L4) and proximal femur (femoral neck) using DEXA Norland XR-46, and was analyzed following stratification by gender. The short-term coefficient of variation for repeated measurements of BMD of this machine was $\sim 0.8 \%$.

Statistical analysis. The comparisons of outcome measures between the intervention and the control groups were performed on an intention-to-treat (ITT) basis, where the outcome measures that were not followed-up were treated as unchanged during the intervention period. All the measured parameters, including age, height, weight, BMI, knowledge (OKT scores) and health beliefs (OHBS scores) of osteoporosis, VAS scores, SF-36 scores and BMD, were presented as the mean \pm SD. The differences between the intervention and control groups were analyzed using independent sample t tests, whereas the within-group analysis between the pre- and post-intervention assessments was undertaken using paired samples $t$ tests. All of the count data, comprising gender, behavior of living and medication compliance data, were analyzed using the $\chi^{2}$ test to compare the differences of the rates between the osteoporosis club and the control group. 
All of the analyses were performed using SPSS version 17.0 (SPSS Inc., Chicago, IL, USA). P $<0.05$ was used to indicate a statistically significant difference.

\section{Results}

General information. Of the 436 participants enrolled, 392 (204 in the osteoporosis club and 188 in the control group) underwent their final follow-up after four years. The differences in the general information (age, height, weight and BMI) between the osteoporosis club and the control groups were not significant $(\mathrm{P}>0.05$; Table I).

Knowledge and health beliefs. No differences in the OKT and OHBS scores were identified between the osteoporosis club and the control groups in the pre-intervention assessment. However, the differences in the OKT and OHBS scores between the two groups in the post-intervention assessment were significant $(\mathrm{P}<0.01$; Table II $)$. Table II demonstrates that the OKT and OHBS scores of the osteoporosis club group were higher compared with those of the control group in the post-intervention assessment, thereby suggesting that the osteoporosis knowledge and health belief levels of the osteoporosis club participants were higher compared with those of the control group. Furthermore, the OKT scores of both groups in the post-intervention assessment were significantly higher compared with those in the pre-intervention assessment $(\mathrm{P}<0.01)$, whereas only the OHBS scores of the osteoporosis club group in the post-intervention assessment were significantly higher compared with the pre-intervention assessment $(\mathrm{P}<0.01$; Table II).

Living behavior. The differences in the living behavior between the osteoporosis club and the control groups in the post-intervention assessment, comprised of sufficient outdoor sunshine ( $\geq 4 \mathrm{~h} /$ week), drinking milk daily ( $\geq 250 \mathrm{ml}$ ), adequate exercise ( $\geq 3$ times/week), no alcohol intake and no smoking, were significant $(\mathrm{P}<0.05$; Table III). Table III demonstrates that the number of participants from the osteoporosis club group with good living behavior for osteoporosis prevention was greater compared with the control group. In addition, all the general behavior was significantly improved in the osteoporosis club post-intervention compared with pre-intervention $(\mathrm{P}<0.01)$, whereas only three items (outdoor sunshine, drinking milk daily and exercise) were significantly improved in the control group post-intervention compared with pre-intervention $(\mathrm{P}<0.01)$.

Medication compliance. A significant difference was identified in the medication compliance between the osteoporosis club and the control groups in the post-intervention assessment $(\mathrm{P}<0.01$; Table IV). Table IV demonstrates that the number of participants in the osteoporosis club group who continued to receive medication therapy was greater than the control group.

Pain degree evaluation and appraisal of life quality. No differences were identified in the VAS and SF-36 scores between the osteoporosis club and the control groups in the pre-intervention assessment. However, the differences in the VAS and SF-36 scores between the osteoporosis club and

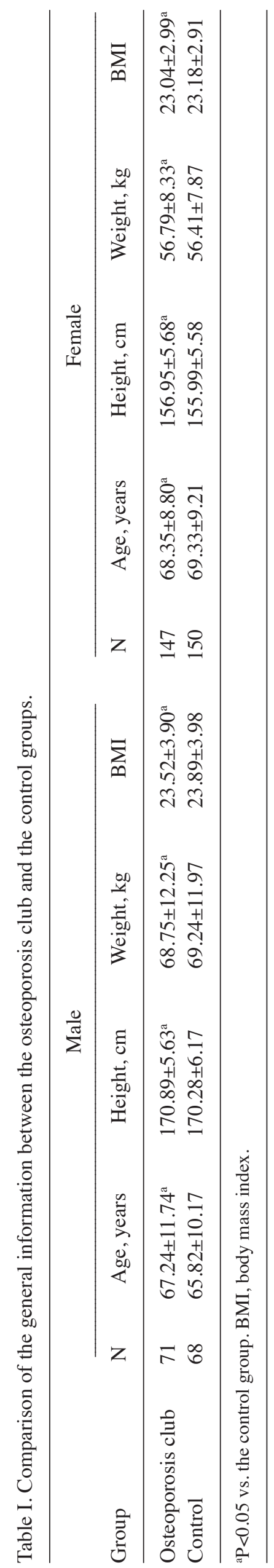


Table II. Comparison of the OKT and OHBS scores between the osteoporosis club and the control group (mean \pm s).

\begin{tabular}{lccrrr}
\hline Scores & Intervention & Osteoporosis club group $(\mathrm{n}=218)$ & Control group $(\mathrm{n}=218)$ & $\mathrm{t}$-value & P-value \\
\hline \multirow{2}{*}{ OKT } & Pre & $12.74 \pm 2.99$ & $13.12 \pm 2.71$ & -1.374 & 0.17 \\
& Post & $21.91 \pm 2.25^{\mathrm{a}}$ & $15.04 \pm 2.66^{\mathrm{a}}$ & 29.146 & $<0.001$ \\
\multirow{2}{*}{ OHBS } & Pre & $149.32 \pm 11.59$ & $149.49 \pm 11.47$ & -0.150 & 0.881 \\
& Post & $156.56 \pm 11.90^{\mathrm{a}}$ & $150.12 \pm 14.58$ & 5.047 & $<0.001$ \\
\hline
\end{tabular}

${ }^{\mathrm{a}} \mathrm{P}<0.01$ vs. pre-intervention. OKT, osteoporosis knowledge test; OHBS, Osteoporosis Health Belief Scale.

Table III. Comparison of the living behavior between the osteoporosis club and the control group.

\begin{tabular}{|c|c|c|c|c|c|c|c|c|}
\hline \multirow[b]{2}{*}{ Living behavior } & \multicolumn{4}{|c|}{ Pre-intervention } & \multicolumn{4}{|c|}{ Post-intervention } \\
\hline & $\begin{array}{l}\text { Control } \\
(\mathrm{n}=218)\end{array}$ & $\begin{array}{l}\text { Osteoporosis club } \\
\quad(\mathrm{n}=218)\end{array}$ & $\chi^{2}$ & P-value & $\begin{array}{l}\text { Control } \\
(\mathrm{n}=218)\end{array}$ & $\begin{array}{l}\text { Osteoporosis club } \\
\quad(\mathrm{n}=218)\end{array}$ & $\chi^{2}$ & P-value \\
\hline $\begin{array}{l}\text { Sufficient outdoor sunshine, } \\
\geq 4 \mathrm{~h} / \text { week }\end{array}$ & 43 & 39 & 0.240 & 0.624 & $94^{\mathrm{a}}$ & $164^{\mathrm{a}}$ & 46.520 & $<0.001$ \\
\hline $\begin{array}{l}\text { Drinking milk everyday, } \\
\geq 250 \mathrm{ml}\end{array}$ & 37 & 43 & 0.551 & 0.458 & $112^{\mathrm{a}}$ & $183^{\mathrm{a}}$ & 51.174 & $<0.001$ \\
\hline $\begin{array}{l}\text { Adequate exercise, } \\
\geq 3 \text { times/week }\end{array}$ & 75 & 70 & 0.258 & 0.611 & $103^{\mathrm{a}}$ & $153^{\mathrm{a}}$ & 23.655 & $<0.001$ \\
\hline No alcohol intake & 171 & 175 & 0.224 & 0.636 & 183 & $203^{\mathrm{a}}$ & 9.036 & 0.003 \\
\hline No smoking & 159 & 168 & 0.991 & 0.320 & 171 & $194^{\mathrm{a}}$ & 8.900 & 0.003 \\
\hline
\end{tabular}

${ }^{\mathrm{a}} \mathrm{P}<0.05$ vs. pre-intervention.

Table IV. Comparison of medication compliance between the osteoporosis club and the control group.

\begin{tabular}{lccr}
\hline Group & Medication therapy $^{\mathrm{a}}$ & No medication therapy $^{\mathrm{b}}$ & $\chi^{2}$ \\
\hline Osteoporosis club $(\mathrm{n}=218)$ & 203 & 15 & 86.871 \\
Control $(\mathrm{n}=218)$ & 117 & 101 & $<0.001$ \\
\hline
\end{tabular}

${ }^{a}$ Number of those who continued medication therapy; ${ }^{b}$ number of those who did not continue medication therapy.

Table V. Comparison of the VAS scores between the osteoporosis club and the control group (mean $\pm \mathrm{s})$.

\begin{tabular}{lccr}
\hline VAS scores & $\begin{array}{c}\text { Control group } \\
(\mathrm{n}=218)\end{array}$ & $\begin{array}{c}\text { Osteoporosis club } \\
\text { group }(\mathrm{n}=218)\end{array}$ & t-value \\
\hline Pre-intervention & $5.08 \pm 2.11$ & $5.04 \pm 2.17$ & -0.201 \\
Post-intervention & $4.13 \pm 1.89^{\mathrm{a}}$ & $1.98 \pm 1.55^{\mathrm{a}}$ & -12.929 \\
\hline
\end{tabular}

${ }^{a} \mathrm{P}<0.01$ vs. pre-intervention. VAS, visual analogue scales.

the control groups in the post-intervention assessment were significant $(\mathrm{P}<0.01)$ (Tables $\mathrm{V}$ and $\mathrm{VI})$. Table $\mathrm{V}$ demonstrates that the VAS scores of the osteoporosis club group were lower compared with the control group in the post-intervention assessment. Furthermore, the VAS scores of the two groups at post-intervention assessment were significantly higher compared with pre-intervention assessment $(\mathrm{P}<0.01)$. Table VI demonstrates that each domain of the SF-36 score of the osteoporosis club group was higher compared with the control group in the post-intervention assessment. In addition, each domain of the SF-36 score of the osteoporosis club group in the post-intervention assessment was significantly higher 
Table VI. Comparison of the SF-36 scores between the osteoporosis club and the control group (mean \pm s).

\begin{tabular}{|c|c|c|c|c|c|c|c|c|}
\hline \multirow[b]{2}{*}{$\begin{array}{l}\text { SF-36 } \\
\text { scores }\end{array}$} & \multicolumn{4}{|c|}{ Pre-intervention } & \multicolumn{4}{|c|}{ Post-intervention } \\
\hline & $\begin{array}{l}\text { Control } \\
(\mathrm{n}=218)\end{array}$ & $\begin{array}{l}\text { Osteoporosis club } \\
\quad(\mathrm{n}=218)\end{array}$ & $\mathrm{t}$-value & P-value & $\begin{array}{l}\text { Control } \\
(\mathrm{n}=218)\end{array}$ & $\begin{array}{l}\text { Osteoporosis club } \\
\quad(\mathrm{n}=218)\end{array}$ & $\mathrm{t}$-value & P-value \\
\hline PF & $73.90 \pm 10.92$ & $74.24 \pm 11.33$ & 0.323 & 0.747 & $74.82 \pm 8.27$ & $81.42 \pm 8.09^{\mathrm{a}}$ & 8.429 & $<0.001$ \\
\hline $\mathrm{RP}$ & $72.94 \pm 18.63$ & $72.82 \pm 19.74$ & -0.062 & 0.950 & $73.28 \pm 18.74$ & $78.21 \pm 18.78^{\mathrm{a}}$ & 2.744 & 0.006 \\
\hline $\mathrm{BP}$ & $61.97 \pm 12.91$ & $62.63 \pm 13.29$ & 0.528 & 0.598 & $62.23 \pm 13.07$ & $70.48 \pm 14.13^{\mathrm{a}}$ & 6.332 & $<0.001$ \\
\hline GH & $69.97 \pm 10.11$ & $70.44 \pm 10.22$ & 0.471 & 0.638 & $70.46 \pm 9.98$ & $75.21 \pm 7.95^{\mathrm{a}}$ & 5.495 & $<0.001$ \\
\hline VT & $67.04 \pm 8.24$ & $66.79 \pm 8.59$ & -0.313 & 0.754 & $68.05 \pm 8.64$ & $72.91 \pm 6.54^{\mathrm{a}}$ & 6.626 & $<0.001$ \\
\hline $\mathrm{SF}$ & $79.76 \pm 14.63$ & $80.22 \pm 14.62$ & 0.327 & 0.744 & $80.96 \pm 14.26$ & $86.07 \pm 14.35^{\mathrm{a}}$ & 3.724 & $<0.001$ \\
\hline $\mathrm{RE}$ & $78.44 \pm 19.96$ & $79.82 \pm 19.74$ & 0.724 & 0.470 & $79.97 \pm 20.02$ & $84.71 \pm 18.68^{\mathrm{a}}$ & 2.556 & 0.011 \\
\hline RH & $77.52 \pm 10.16$ & $78.94 \pm 9.79$ & 1.478 & 0.140 & $78.00 \pm 10.68$ & $85.58 \pm 9.38^{\mathrm{a}}$ & 7.871 & $<0.001$ \\
\hline
\end{tabular}

${ }^{a} \mathrm{P}<0.001$ vs. the pre-intervention. SF-36, Short Form Health Survey; PF, physical functioning; RP, role physical; BP, bodily pain; GH, general health; VT, vitality; SF, social functioning; RE, role emotional.

compared with the pre-intervention assessment $(\mathrm{P}<0.05)$, whereas the difference in the control group was not significant $(\mathrm{P}>0.05)$.

Bone mineral density. No differences were identified in the BMD between the osteoporosis club and the control groups in the pre-intervention assessment $(\mathrm{P}>0.05$; Tables VII and VIII). The differences in the BMD measured at the lumbar spine (L2-L4) and proximal femur (femoral neck) of both male and female participants between the two groups in the post-intervention assessment were significant $(\mathrm{P}<0.01$; Tables VII and VIII). Tables VII and VIII demonstrate that the BMD values of the osteoporosis club group (both male and female) were higher compared with the control group in the post-intervention assessment. In addition, the BMD values of the osteoporosis club group (both male and female) in the post-intervention assessment were significantly higher compared with the pre-intervention assessment $(\mathrm{P}<0.01)$, whereas the difference in the control group was not significant $(\mathrm{P}>0.05)$.

\section{Discussion}

The results in the present study confirm that the model of health education and management of osteoporosis prevention by setting up an osteoporosis club has a statistically significant effect on the knowledge and health beliefs on osteoporosis, living behavior, medication compliance, pain degree, quality of life and BMD. The observations indicate that the model of setting up an osteoporosis club is an evidence-based practice of health education and management for osteoporosis prevention.

The current study is, to the best of our knowledge, the first to set up a club for osteoporosis education and management in China, which adopted a unified management of membership based on a digitized database. The model would be effective for a Chinese population, particularly due to the serious challenge of the ageing population in China. The present study shows the immediate effect of the intervention on improving the health education and management of osteoporosis prevention and long-term observations that lasted for four years. To provide a multi-aspect and systematic osteoporosis education and management, the osteoporosis club organized an integrated team of training specialists composed of orthopedists, nutritionists, endocrinologists and rehabilitation therapists. These training specialists were required to acquire the necessary knowledge for implementing recommendations and to seek education to increase their skills $(25,26)$. In the present study, the training specialists were required to attend regular continuing education workshops that covered information with regards to the latest research on osteoporosis, current treatment methods and management options, basic nutrition for healthy bones, exercises for osteoporosis, psychological health and education skills and strategies. The patients shared experiences in the workshop and learned from one another how to improve the quality of training lectures. However, a small number of participants were withdrawn from the study due to the lack of follow-up. Thus, the osteoporosis club regularly held educational seminars to incorporate behavioral theories and strategies in order to increase participant adherence to the program. The outcome measures of the intervention and control groups were compared on an ITT basis in order to reduce bias.

Osteoporosis is a 'silent' disease (27), which results in fragility fractures in patients without them realizing due to poor or limited knowledge. Therefore, a good knowledge on osteoporosis is required for its prevention (28). The present study reveals that participants had a limited knowledge and health beliefs of osteoporosis in the pre-intervention assessment, which means they had a high risk of fragility fractures. The osteoporosis club organized an integrated team of training specialists and provided systematic osteoporosis education to increase the knowledge on osteoporosis. The present study proved that the intervention could increase the knowledge of osteoporosis, and a significant correlation was identified on the level of knowledge, health beliefs and education in those pre- and post-assessment. The model was as effective as those reported in previous studies $(8,29,30)$, thereby suggesting that 

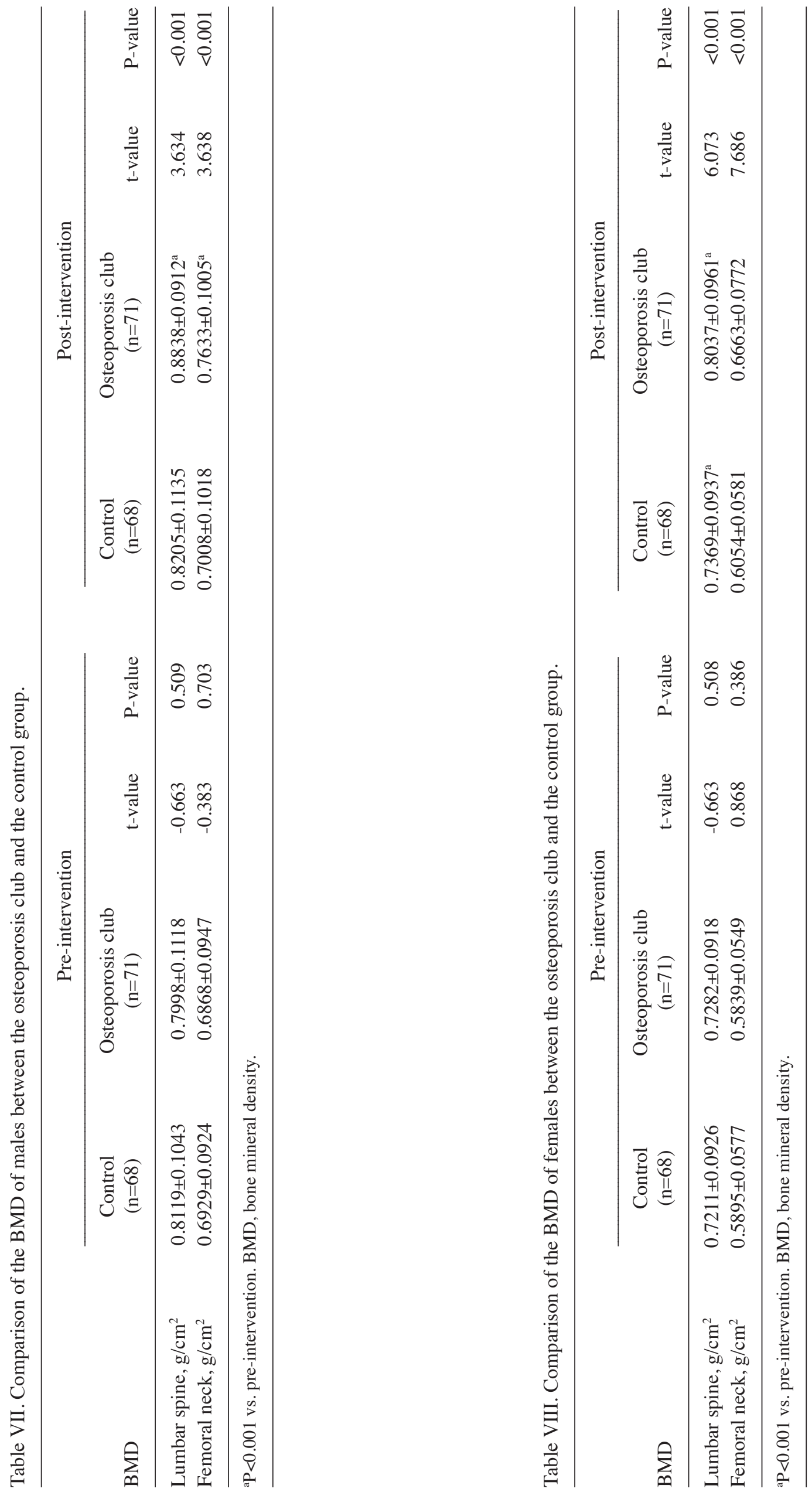
the osteoporosis club education is a valid protocol to improve the knowledge of osteoporosis and health beliefs. Furthermore, the OKT scores of the self-management control group at post-intervention assessment were higher compared with the pre-intervention assessment, whereas the OHBS scores did not change significantly. The possible reason for this observation is that due to the wide public promotion of osteoporosis knowledge in China, the patients would obtain more information on osteoporosis but pay less attention to it.

Osteoporosis is a chronic disease similar to hypertension and diabetes, which requires sustained treatment; thus, compliance is key for osteoporosis prevention. However, a high level of knowledge of osteoporosis does not always indicate good compliance. Based on the study by Hernandez-Rauda and Martinez-Garcia (31), knowledge is not associated with preventive health habits, including sufficient calcium intake and performance of weight-bearing physical activities. In the study by Etemadifar et al (32), patients with a high education level had significantly better knowledge on osteoporosis compared with those with a low educational level. However, they did not use this knowledge during their lifetime. Among the participants with a high education level, $95.9 \%$ did not exercise regularly, $97.6 \%$ and $98.2 \%$ did not have an adequate intake of calcium and vitamin D supplements, respectively, and only $19.8 \%$ regularly drank milk on a daily basis. The present study evaluated medication compliance by recording the numbers of those who continued medication therapy and assessed their living behavior, comprising of sufficient outdoor sunshine ( $\geq 4 \mathrm{~h} /$ week), daily milk intake ( $\geq 250 \mathrm{ml}$ ), adequate exercise ( $\geq 3$ times/week), no alcohol intake and no smoking, which are indirect indexes of compliance. The results of the present study revealed that the participants in the osteoporosis club group had much better living behavior and medication compliance compared with those of the control group, thereby suggesting that the osteoporosis club education and management could enhance the compliance for osteoporosis prevention. This observation was similar to the study by Terrio and Auld (29) in the United States where calcium intake was sufficient in the majority of the cases.

Quality of life has been considered an important assessment index of the therapeutic effect on patients with osteoporosis (33-35). The present study evaluated the effect of the osteoporosis club education and management on the quality of life using the SF-36 questionnaire and VAS scores. The results confirmed that the quality of life of the osteoporosis club participants was improved compared with that of the control group in the post-intervention assessment. An earlier study by Olsen and Bergland (22), which reported a similar result, demonstrated that the fear of falling was reduced and the quality of life increased following educational sessions and exercises.

BMD is the most important index for osteoporosis management as it is being a primary predictor of osteoporotic fracture $(36,37)$. Thus, BMD is regularly used to evaluate the effectiveness of osteoporosis education and management $(13,38)$. An earlier study by Winzenberg et al (9) revealed that fracture risk feedback based on BMD could potentially make an important contribution to osteoporosis prevention. The present study revealed that the BMD of the osteoporosis club group was higher compared wth the control group post-intervention, which indicated that the osteoporosis club education and management was effective in increasing BMD and decreasing the rates of osteoporosis-related fragility fractures.

Nevertheless, the present study has a number of limitations. Initially, it did not adopt a double-blind design due to it being impossible for the control group to use a placebo intervention, and the osteoporosis club group had integrated education and management. In addition, it did not include a measurement of the fragility fracture rates, which is one of the greatest threats to the quality of life and mortality rate of patients with osteoporosis. Hence, a possible bias may be created with regard to the assessment of the effect of the intervention. Instead, the change in BMD, which is a primary predictor of osteoporotic fracture $(36,37)$, was studied. Finally, the sample size was relatively small, and the results should be considered with caution.

The present study, where an osteoporosis club was established, introduced a model of health education and management for Chinese osteoporosis prevention, and the limitations remain to be studied further. Other evaluation indexes of the effectiveness of the intervention could be used, including muscle function and performance (13), rate of fragility fracture, social participation and mortality rate. In addition, more samples should be observed.

In conclusion, the observations of the present study indicate that the osteoporosis club education and management, which adopts a unified management of membership based on a digital database and includes systematic health education lectures once a month, exercise programs and communication parties once a year, is an evidence-based model of health education and management for Chinese osteoporosis prevention.

\section{References}

1. Prevention and management of osteoporosis. World Health Organ Tech Rep Ser 921: 1-164, 2003.

2. Johnell $\mathrm{O}$ and Kanis JA: An estimate of the worldwide prevalence and disability associated with osteoporotic fractures. Osteoporos Int 17: 1726-1733, 2006.

3. Committee for Osteoporosis Treatment of the Japanese Orthopaedic Association: Nationwide survey of hip fractures in Japan. J Orthop Sci 9: 1-5, 2004.

4. Haleem S, Lutchman L, Mayahi R, Grice JE and Parker MJ: Mortality following hip fracture: Trends and geographical variations over the last 40 years. Injury 39: 1157-1163, 2008.

5. Gullberg B, Johnell O and Kanis JA: World-wide projections for hip fracture. Osteoporos Int 7: 407-413, 1997.

6. Cai Y: China's new demographic reality: Learning from the 2010 census. Popul Dev Rev 39: 371-396, 2013.

7. Peterlik M, Kállay E and Cross HS: Calcium nutrition and extracellular calcium sensing: Relevance for the pathogenesis of osteoporosis, cancer and cardiovascular diseases. Nutrients 5: 302-327, 2013.

8. Jensen AL, Lomborg K, Wind G and Langdahl BL: Effectiveness and characteristics of multifaceted osteoporosis group education - a systematic review. Osteoporos Int 25: 1209-1224, 2014.

9. Winzenberg T, Oldenburg B and Jones G: Bone density testing: An under-utilised and under-researched health education tool for osteoporosis prevention? Nutrients 2: 985-996, 2010.

10. Tamaki J and Iki M: Evidence-based, best-practice guidelines for primary prevention of osteoporosis and osteoporotic fractures. Clin Calcium 15: 1312-1318, 2005 (In Japanese).

11. Nakatani Y, Tamaki J, Komatsu M, Iki M and Kajita E: Effect of distributing an evidence-based guideline for prevention of osteoporosis on health education programs in municipal health centers: A randomized controlled trial. J Epidemiol 22: 103-112, 2012. 
12. Balasubramanian A, Tosi LL, Lane JM, Dirschl DR, Ho PR and O'Malley CD: Declining rates of osteoporosis management following fragility fractures in the U.S., 2000 through 2009. J Bone Joint Surg Am 96: e52, 2014.

13. Gianoudis J, Bailey CA, Sanders KM, Nowson CA, Hill K, Ebeling PR and Daly RM: Osteo-cise: Strong bones for life: Protocol for a community-based randomised controlled trial of a multi-modal exercise and osteoporosis education program for older adults at risk of falls and fractures. BMC Musculoskelet Disord 13: 78, 2012.

14. Kanis JA: Assessment of fracture risk and its application to screening for postmenopausal osteoporosis: Synopsis of a WHO report. WHO study group. Osteoporos Int 4: 368-381, 1994.

15. Silverman SL: Quality-of-life issues in osteoporosis. Curr Rheumatol Rep 7: 39-45, 2005.

16. Guillemin F, Martinez L, Calvert M, Cooper C, Ganiats T, Gitlin M, Horne R, Marciniak A, Pfeilschifter J, Shepherd S, et al: Fear of falling, fracture history, and comorbidities are associated with health-related quality of life among European and US women with osteoporosis in a large international study. Osteoporos Int 24: 3001-3010, 2013.

17. Borer KT: Physical activity in the prevention and amelioration of osteoporosis in women: Interaction of mechanical, hormonal and dietary factors. Sports Med 35: 779-830, 2005.

18. Werner P: Knowledge about osteoporosis: Assessment, correlates and outcomes. Osteoporos Int 16: 115-127, 2005

19. Kim KK, Horan ML, Gendler P and Patel MK: Development and evaluation of the Osteoporosis Health Belief Scale. Res Nurs Health 14: 155-163, 1991

20. Ford MA, Bass M, Zhao Y, Bai JB and Zhao Y: Osteoporosis knowledge, self-efficacy and beliefs among college students in the USA and China. J Osteoporos 2011: 729219, 2011.

21. Reips UD and Funke F: Interval-level measurement with visual analogue scales in internet-based research: VAS Generator Behav Res Methods 40: 699-704, 2008

22. Olsen CF and Bergland A: The effect of exercise and education on fear of falling in elderly women with osteoporosis and a history of vertebral fracture: Results of a randomized controlled trial. Osteoporos Int 25: 2017-2025, 2014.

23. Lix LM, Acan Osman B, Adachi JD, Towheed T, Hopman W, Davison KS and Leslie WD: Measurement equivalence of the SF-36 in the Canadian multicentre osteoporosis study. Health Qual Life Outcomes 10: 29, 2012.

24. Li L, Wang H and Shen Y: Development and psychometric tests of a Chinese version of the SF-36 health survey scales. Zhonghua Yu Fang Yi Xue Za Zhi 36: 109-113, 2002.
25. Gurses AP, Seidl KL, Vaidya V, Bochicchio G, Harris AD, Hebden J and Xiao Y: Systems ambiguity and guideline compliance: A qualitative study of how intensive care units follow evidence-based guidelines to reduce healthcare-associated infections. Qual Saf Health Care 17: 351-359, 2008.

26. Prior M, Guerin M and Grimmer-Somers K: The effectiveness of clinical guideline implementation strategies - a synthesis of systematic review findings. J Eval Clin Pract 14: 888-897, 2008.

27. Varner JM: Osteoporosis: A silent disease. Ala Nurse 39: 10-11; quiz 11-2, 2012.

28. Díaz-Correa LM, Ramírez-García LM, Castro-Santana LE and Vilá LM: Osteoporosis knowledge in patients with a first fragility fracture in Puerto Rico. Bol Asoc Med P R 106: 6-10, 2014.

29. Terrio K and Auld GW: Osteoporosis knowledge, calcium intake, and weight-bearing physical activity in three age groups of women. J Community Health 27: 307-320, 2002.

30. Geller SE and Derman R: Knowledge, beliefs, and risk factors for osteoporosis among African-American and Hispanic women. J Natl Med Assoc 93: 13-21, 2001.

31. Hernandez-Rauda R and Martinez-Garcia S: Osteoporosis-related life habits and knowledge about osteoporosis among women in El Salvador: A cross-sectional study. BMC Musculoskelet Disord 5: 29, 2004

32. Etemadifar MR, Nourian SM, Fereidan-Esfahani M, Shemshaki H, Nourbakhsh M and Zarezadeh A: Relationship of knowledge about osteoporosis with education level and life habits. World J Orthop 4: 139-143, 2013.

33. Kanis JA, Minne WH, Meunier PJ, Ziegler R and Allender E: Quality of life and vertebral osteoporosis. Osteoporos Int 2: 161-163, 1992.

34. Silverman SL and Cranney A: Quality of life measurement in osteoporosis. J Rheumatol 24: 1218-1221, 1997.

35. Papaioannou A, Kennedy CC, Ioannidis G, Brown JP, Pathak A, Hanley DA, Josse RG, Sebaldt RJ, Olszynski WP, Tenenhouse A, et al: Determinants of health-related quality of life in women with vertebral fractures. Osteoporos Int 17: 355-363, 2006.

36. Marshall D, Johnell O and Wedel H: Meta-analysis of how well measures of bone mineral density predict occurrence of osteoporotic fractures. BMJ 312: 1254-1259, 1996.

37. Nguyen T, Sambrook P, Kelly P, Jones G, Lord S, Freund J and Eisman J: Prediction of osteoporotic fractures by postural instability and bone density. BMJ 307: 1111-1115, 1993.

38. Goh LH, How CH and Lau TC: Male osteoporosis: Clinical approach and management in family practice. Singapore Med J 55: 353-357, 2014. 